COMUNICAÇÃO CIENTÍFICA

\title{
ABACAXI 'TURIAÇU': CULTIVAR TRADICIONAL NATIVA DO MARANHÃO ${ }^{1}$
}

\author{
JOSÉ RIBAMAR GUSMÃO ARAUJO², ROZALINO ANTONIO AGUIAR JÚNIOR ${ }^{3}$, \\ AFONSO MANOEL SILVA CHAVES ${ }^{2}$, FABRÍCIO DE OLIVEIRA REIS ${ }^{3}$, \\ MOISÉS RODRIGUES MARTINS ${ }^{2}$
}

RESUMO - Objetivou-se caracterizar a biometria da planta e analisar física e quimicamente frutos de abacaxi da cultivar Turiaçu e proceder à análise comparativa com outras cultivares tradicionais e melhoradas. Trata-se de uma seleção nativa da Amazônia Maranhense que apresenta importância socioeconômica no Estado do Maranhão. As plantas e frutos foram avaliados no período de 2007 a 2009, em um experimento de campo, no espaçamento de $1,0 \times 0,40 \mathrm{~m}$, para o qual se utilizaram mudas tipo filhote com $35 \mathrm{a} 40 \mathrm{~cm}$ de comprimento. Os dados foram analisados por técnicas da estatística descritiva, obtendo-se a média de cada caráter e os coeficientes de correlação linear simples entre nove caracteres priorizados. Os resultados indicam que o peso médio do fruto de $1.620 \mathrm{~g}$, coroa média, o teor de sólidos solúveis totais de $16,1{ }^{\circ} \mathrm{Brix}$ e a coloração amarela da polpa configuram um produto que atende às exigências comerciais. $\mathrm{O}$ teor de acidez é baixo, requerendo ajuste no ponto de colheita para aproveitamento industrial. A elevada produção de filhotes por planta assegura a renovação das áreas de cultivo.

Termos para indexação: Ananas comosus var. comosus, frutas nativas, biometria de planta, qualidade do fruto de abacaxi.

\section{TURIAÇU: A PINEAPPLE CULTIVAR TRADITIONAL AND NATIVE FROM MARANHÃO, BRAZIL}

ABSTRACT - Characterize the biometry of plant and analyze physical and chemically pineapple fuits of Turiaçu cultivar and proceed comparative analysis with others traditional and improved cultivars, were the main objectives of this study. 'Turiaçu' is considered a native selection from Eastern Amazon Basin and of great importance to Maranhão State. The field experiment was conduced from 2007 to 2009, using spacing in simple rows of $1.0 \times 0.40 \mathrm{~m}$. The medium-slips for planting got 35 to $40 \mathrm{~cm}$. The data were analyzed by descriptive statistics leading to get average of each character and the coefficient of linear correlation between nine main characters. The average fruit weigth $(1620,0 \mathrm{~g})$, medium crown, total soluble solids content $\left(16.1^{\circ} \mathrm{Brix}\right)$ and the pulp of yellow collor, configure a product suitable to market exigencies. The acidity content is lower than other cultivars, requiring adjust in harvest point aiming industrial uses. The hight production of slips per planta assure cultivation of new areas.

Index terms: Ananas comosus var. comosus, native fruit, plant biometry, fruit quality of pineapple.

O Brasil é o segundo maior produtor mundial de abacaxi [Ananas comosus var. comosus (L.) Merril], respondendo por $15 \%$ da produção mundial, equivalente a 1.470,3 mil toneladas e área plantada de 60.016 ha em 2010 (IBGE, 2010). Atualmente, as Filipinas figuram como maior produtor, vindo na terceira posição a Costa Rica (FAO, 2010). O Maranhão ocupa a quarta posição em produção e área de abacaxi no Nordeste, com 1.218 ha, representando $5,4 \%$ da área do Nordeste, que por sua vez responde por $37,2 \%$ da área cultivada no País. O rendimento médio da cultura no Estado é de $19.445 \mathrm{~kg} \mathrm{ha}^{-1}$, contra $27.014 \mathrm{~kg} \mathrm{ha}^{-1}$ do Nordeste e de $29.456 \mathrm{~kg} \mathrm{ha}^{-1}$ da Paraíba, atualmente o maior produtor nacional.

No Maranhão, a Mesorregião Central é a mais tradicional no cultivo do abacaxi, com destaque

\footnotetext{
'(Trabalho 126-12). Recebido em: 09-04-2012. Aceito para publicação em: 16-10-2012.

${ }^{2}$ Professores do Depto. de Fitotecnia e Fitossanidade do Centro de Ciências Agrárias da Universidade Estadual do Maranhão. Av. Lourenço Vieira da Silva, S/N. CEP: 65.055-970, São Luís-MA. E-mails:gusmao@elo.com.br, fareoli@gmail.com, martinsbeq@ yahoo.com.br

${ }^{3}$ Estudante de graduação em Engenharia Agronômica - Universidade Estadual do Maranhão. Av. Lourenço Vieira da Silva, S/N. CEP: 65.055-970, São Luís-MA. E-mails: rozalinoaguiar@gmail.com, afonso.m.s@hotmail.com
} 
para a cultivar 'Pérola', onde os municípios de São Domingos do Maranhão (808 ha), Tuntum (45 ha) e Grajaú (30 ha) respondem, juntos, por $70,2 \%$ da área cultivada no Estado (IBGE, 2010). Mais recentemente, tem crescido a exploração da cultivar 'Turiaçu', concentrada no município de Turiaçu, com área atual de 149 ha (12,0\% do total), sendo este o segundo maior produtor estadual.

Conforme Ferreira et al. (2010), o Brasil é um dos maiores centros de diversidade genética de abacaxi do mundo, contemplando, além de Ananas comosus, diversas espécies de Ananas e alguns gêneros próximos, como Pseudananas e Bromelia, todas de ocorrência endêmica em várias regiões brasileiras, apresentando ampla variabilidade genética, notadamente da região Amazônica. $\mathrm{O}$ centro de diversidade do gênero Ananas atualmente se restringe a áreas localizadas entre as latidudes $10^{\circ} \mathrm{N}$ e $10^{\circ} \mathrm{S}$ e $55^{\circ} \mathrm{W}$ e $75^{\circ} \mathrm{W}$ de longitude.

Há um permanente esforço da pesquisa em relação aos trabalhos de prospecção e domesticação de novas cultivares ou seleções clonais de abacaxizeiro e outras fruteiras nativas da região Amazônica e do Cerrado (FERREIRA et al, 2010; SPIRONELLO, 2010 ; ), além do melhoramento genético por meio da hibridação (CABRAL et al., 2009), visando a gerar genótipos resistentes à fusariose causada pelo fungo Fusarium subglutinans f.sp. ananas, apresentando folhas lisas e frutos de qualidade superior (VENTURA et al., 2009; CABRAL;MATOS, 2009). Outras estratégias incluem a introdução e avaliação de cultivares em regiões produtoras (SAMPAIO et al., 2011), assim como a seleção de espécies e híbridos ornamentais visando a alcançar outros mercados (SOUZA et al., 2007).

$\mathrm{Na}$ linha de prospecção, caracterização e seleção de materiais regionais visando a suprir a demanda por boas cultivares, destaca-se, no Maranhão, o abacaxi Turiaçu. A referida cultivar é nativa do município de Turiaçu, localizado na Microrregião do Gurupi (Amazônia Maranhense) a $1^{\circ}$ de latitude sul, selecionada por agricultores familiares e que se encontra em processo de domesticação e de inovações em seu sistema produtivo. Os frutos da referida cultivar são muito apreciados no mercado consumidor regional, devido ao elevado teor de açúcares, peso médio e polpa amarela, mas ainda é cultivada com técnicas rústicas e tradicionais, em que predomina o plantio sem espaçamento definido, baixa densidade de plantas e colheita desorganizada, normalmente com frutos em elevado estádio de maturação. Somente a partir de 2006, tiveram início as pesquisas de campo com o abacaxi Turiaçu, visando a caracterizar a variedade em seus aspectos botânicos, morfológicos e fitotécnicos, e desenvolver tecnologias visando a aumentar a produtividade da cultura e a definir um padrão de qualidade dos frutos.

A ocorrência de espécies e variedades de Ananas em baixas latitudes entre $10^{\circ} \mathrm{Ne} 10^{\circ} \mathrm{S}$ é citada por vários autores, conforme revisaram Crestani et al. (2010). Spironello (2010) refere-se ao acesso 'Alto Turi' entre as 21 espécies selvagens e 54 acessos de Ananas comosus introduzidos no Banco Ativo de Germoplasma (BAG) do IAC na década de 70 . Provavelmente, este acesso refere-se ao abacaxi Turiaçu, oriundo da região administrativa do Estado denominada Alto Turi, na mesma Microrregião do Gurupi, onde se situa o município de Turiaçu. Conforme Araújo et al .(2007), a origem do abacaxi Turiaçu ainda apresenta controvérsia, mas os estudos apontam para uma seleção local, inicialmente domesticada pelos índios e em seguida propagada em larga escala por pequenos agricultores.

O presente trabalho objetivou a caracterização biométrica da planta e físico-química de frutos de abacaxi da cultivar Turiaçu e proceder à análise comparativa com outras variedades tradicionais e melhoradas.

O trabalho foi conduzido no povoado de Serra dos Paz, município de Turiaçu-MA, no período de 2007 a 2009. O município, pertencente à microrregião do Gurupi, localiza-se nas coordenadas geográficas de latitude $01^{\circ} 39^{\prime} 48^{\prime \prime}$ e longitude de $45^{\circ} 22^{\prime} 18^{\prime}$ ". O clima da região, segundo classificação de Köppen é do tipo Aw', semiúmido, com temperatura média anual de $26,4^{\circ} \mathrm{C}$, umidade relativa do ar de $82 \%$. A precipitação total anual alcança $2.196 \mathrm{~mm}$, sendo $92 \%$ das chuvas distribuídas de janeiro a julho. O preparo do solo constou de limpeza da área, seguida de gradagem a $30 \mathrm{~cm}$ de profundidade. $\mathrm{O}$ solo é classificado como Plintossolo, textura franco argiloarenosa, e a análise química de amostras, retiradas na camada de $0-20 \mathrm{~cm}$, apresentou os seguintes resultados: $\mathrm{pH}$ (água) $=5,8 ; \mathrm{P}$ (resina) $=2,1$ $\mathrm{mg} \mathrm{dm}{ }^{-3} ; \mathrm{K}=0,73 \mathrm{mmol}_{\mathrm{c}} \mathrm{dm}^{-3} ; \mathrm{Ca}=21,0 \mathrm{mmol}_{\mathrm{c}} \mathrm{dm}^{-3}$; $\mathrm{Mg}=18,5 \mathrm{mmol}_{\mathrm{c}} \mathrm{dm}^{-3} ; \mathrm{Na}=0,8 \mathrm{mmol}_{\mathrm{c}} \mathrm{dm}^{-3} ; \mathrm{H}+\mathrm{Al}=$ $52,8 \mathrm{mmol} \mathrm{dm}^{-3} ; \mathrm{SB}=41,0 \mathrm{mmol} \mathrm{dm}^{-3} ; \mathrm{CTC}=93,8$ $\mathrm{mmol}_{\mathrm{c}} \mathrm{dm}^{-3} ; \mathrm{V}(\%)=43,7 ;$ M.O. $=19 \mathrm{~g} \mathrm{~kg}^{-1}$. O plantio foi realizado em covas, utilizando-se de mudas tipo filhote, sadias, com 35 a $40 \mathrm{~cm}$ de comprimento. No plantio, foi utilizado o espaçamento de $1,0 \times 0,40$ $\mathrm{m}$ em fileiras simples. As adubações de plantio com fósforo e de cobertura com nitrogênio e potássio, em três parcelamentos, foram realizadas conforme a recomendação de análise de solo.

Aos 12 meses após o plantio, foi realizada a indução floral com $1 \mathrm{~g}$ de carbureto de cálcio por planta, para uniformizar o florescimento. Os frutos 
maduros (casca com 25 a $50 \%$ de malhas amarelas, sentido base-ápice) foram colhidos aos 18 meses após o plantio, sendo avaliadas as seguintes características biométricas e de qualidade dos frutos: altura da planta (base até a extremidade do pedúnculo, em $\mathrm{cm}$ ); comprimento do fruto e da coroa $(\mathrm{cm})$; diâmetros mediano e do talo ou eixo central $(\mathrm{cm})$; peso do fruto com e sem a coroa (g); peso da coroa $(\mathrm{g})$; comprimento e diâmetro do pedúnculo; rendimento de polpa (\%); forma do fruto e cor da casca e da polpa; produção de mudas; teor de sólidos solúveis totais $\left({ }^{\circ}\right.$ Brix); acidez total titulável do suco (\% ácido cítrico) e pH. Por ocasião do florescimento (12 meses após o plantio), foram mensurados o número de folhas e o comprimento e a largura da folha $\mathrm{D}$. As medidas de diâmetro do fruto e da planta foram realizadas com paquímetro digital. A acidez total titulável foi determinada por titulação com hidróxido de sódio a $0,1 \mathrm{~N}$, utilizando o indicador fenolfatleína a $1 \%$. Para a obtenção do suco, foram multiprocessadas três rodelas de $1 \mathrm{~cm}$ de espessura de cada fruto, referentes às porções apical, mediana e basal. Em seguida, o homogeneizado foi passado em papel de filtro e após filtragem foram retiradas alíquotas de $10 \mathrm{~mL}$ para as análises de $\mathrm{pH}$, sólidos solúveis totais e acidez total titulável, sendo, respectivamente, necessárias uma leitura em peagâmetro, três leituras em refratômetro manual e duas titulações em soda para a obtenção dos dados.

A parcela experimental foi constituída de 85 plantas, sendo a área útil para avaliações e colheita composta de 12 plantas, quatro repetições. Os dados apresentados referem-se ao espaçamento de 1,0 x $0,40 \mathrm{~m}$ (densidade de 25.000 plantas hectare ${ }^{-1}$ ), equivalente àquele adotado pelos produtores. Em razão da variação observada no formato do fruto, realizou-se a comparação estatística da proporção de frutos cilíndricos e cônicos com a aplicação do Teste $t$, a partir da amostragem de frutos colhidos nas diferentes densidades. Foram calculados, ainda, os coeficientes de correlação linear simples de Pearson entre caracteres da planta e do fruto mais representativos. As análises estatísticas foram realizadas por meio do software estatístico Assistat v.7.6 (SILVA; AZEVEDO, 2006).

Para a comparação dos dados biométricos e fisico-químicos obtidos de abacaxi Turiaçu com os de outras variedades ('Pérola', 'Smooth Cayenne' e 'Vitória'), visando a compor as Tabelas 1 e 2, tomaram-se por base os trabalhos de Ventura et al. (2009) e Cabral et al. (2009).

Em relação aos resultados, a cultivar Turiaçu apresenta espinhos nos bordos da folha, semelhante à cultivar Pérola, a mais explorada no Brasil, e diferindo da nova cultivar Vitória, exigindo cuidados na realização de tratos culturais e colheita. As folhas são, no entanto, de comprimento médio e mais estreitas, quase a metade da largura das demais cultivares, sendo necessário o lançamento médio de 61 folhas até o florescimento. A produção de mudas tipo filhote é elevada e similar à da Pérola, mas supera as demais variedades ('Smooth Cayenne' e 'Vitória'), com a média de 11,3 mudas por planta (Tabela 1). Os rebentões são raros, mas a elevada produção de filhotes assegura a renovação e a ampliação das áreas de cultivo, fato relevante para uma nova cultivar.

O comprimento do pedúnculo $(\mathrm{CP})$ é superior às demais cultivares (Tabela 1), mas com diâmetro semelhante. No entanto, em condições de cultivo e em áreas de experimento, não se verificam o tombamento de frutos e a queima solar, em que pese ao pedúnculo ser longo e a maturação dos frutos ocorrer no período de maior luminosidade. Por sua vez, os melhoristas de abacaxi preconizam que os valores de CP devam ser inferiores a 20,0 cm (CABRAL et al., 2009), conforme é verificado no Smooth Cayenne, visando a evitar os problemas citados.

Descrevendo o abacaxi 'Turiaçu', Araújo et al. (2007) observaram, também, a presença de microbrotações na forma de mudinhas na base da coroa e coloração verde-violácea das folhas terminais quando a planta se encontra no estádio de florescimento. Com o botão floral já lançado, as brácteas apresentam coloração vermelho-escarlate. O florescimento natural inicia- se entre 12 e 13 meses após o plantio.

O peso dos frutos do abacaxi 'Turiaçu' enquadra-se no mesmo padrão comercial das demais cultivares (Tabela 2), obtendo peso médio de $1.620 \mathrm{~g}$, valor similar à 'Pérola' e 'Vitória' (VENTURA et al., 2009). O peso médio do abacaxi 'Turiaçu' também é similar à cultivar 'Imperial', híbrido resultante do cruzamento de 'Perolera' com 'Smooth Cayenne' e que tem peso de $1,6 \mathrm{~kg}$ (CABRAL;MATOS, 2009). A massa do fruto da cultivar 'Turiaçu' foi superior aos valores alcançados por cinco cultivares avaliadas por Sampaio et al. (2011), que utilizaram mudas micropropagadas in vitro. $\mathrm{O}$ peso médio do fruto comercial de abacaxi no Brasil varia de 900 a $2.400 \mathrm{~g}$, conforme as normas de classificação oficial (MAPA, 2002). Destaca-se que a coroa do fruto do 'Turiaçu' apresenta comprimento e peso inferiores às demais cultivares, com 14,4 cm e 61,1 $\mathrm{g}$, respectivamente, o que poderá constituir-se numa característica vantajosa no processo de transporte e comercialização. Coroa pequena também resulta no 
maior rendimento de polpa em relação ao peso total do fruto, cujo valor obtido no abacaxi 'Turiaçu' foi de $64,8 \%$ (Tabela 2 ).

A forma do fruto do abacaxi 'Turiaçu' apresenta-se instável, variando entre a cilíndrica e a cônica (Tabela 2), com predominância significativa para a primeira (Figura 1), com proporção de $2 / 3$ dos frutos, cujo padrão se aproxima ao de 'Smooth Cayenne' e de 'Vitória'. Por tratar-se de uma cultivar ainda em processo de domesticação e propagada vegetativamente, os trabalhos de seleção deverão ser direcionados para obtenção de genótipos que atendam ao formato cilíndrico dos frutos, mais apropriados ao processamento.

Considerando 'Pérola' e 'Smooth Cayenne' como cultivares de referência, e mais cultivadas no Brasil, o abacaxi 'Turiaçu', quando maduro, apresenta casca de cor amarelada e polpa amarela (Tabela 2 e Figura 2), características desejadas pelos melhoristas. Neste último caráter, 'Turiaçu' assemelha-se a 'Smotth Cayenne' e a 'Imperial', e difere de 'Pérola' e de 'Vitória'. A partir das normas oficiais de classificação do MAPA (2002), o fruto de abacaxi Turiaçu pode ser enquadrado no grupo Polpa Amarela e subgrupo Casca Amarela, com mais de $50 \%$ dos frutilhos completamente amarelos (Figura 2).

As características físico-químicas do fruto de abacaxi Turiaçu (Tabela 2) confirmam seu potencial para o consumo in natura, apresentando elevado teor de sólidos solúveis totais (média de $16,1^{\circ}$ Brix), baixa acidez (média de $0,38 \%$ ) e elevada relação do teor de açúcares/acidez $(42,3)$. O teor de sólidos totais em diferentes amostras avaliadas variou de 14,4 a $17,9^{\circ}$ Brix, sempre superior ao mínimo exigido pelas normas oficiais, que é de $12,0^{\circ}$ Brix (MAPA, 2002) e também em relação às demais cultivares analisadas, situação favorecida pela elevada temperatura e escassez de chuvas na região, na época de maturação. No entanto, para a industrialização, o ponto de colheita do fruto deverá ser ajustado para um teor de acidez superior a $0,65 \%$ até a faixa de 0,95\%, conforme salientam Cabral et al. (2009). No mercado regional do Maranhão e na capital São Luís, a cotação do preço do abacaxi Turiaçu alcança, em média, o dobro da cultivar 'Pérola', fato relacionado ao sabor mais doce e polpa atrativa, além de a oferta ser concentrada num período mais curto ( 3 a 4 meses), ocorrendo de agosto a novembro.

A análise de correlação linear simples de Pearson entre caracteres da planta e do fruto de abacaxi 'Turiaçu' (Tabela 3) revelou coeficientes elevados e altamente significativos para a combinação do comprimento do pedúnculo com altura da planta e com o número de folhas, além do peso do fruto com o diâmetro do talo ou eixo. A maior altura de planta da cultivar 'Turiaçu' (Tabela 1), em relação às demais cultivares, possivelmente foi devido ao maior comprimento do pedúnculo. Correlação significativa e positiva de média magnitude foi verificada entre o peso do fruto e o peso da coroa, entre o número de folhas e o peso do fruto e entre o diâmetro do pedúnculo e o diâmetro do talo. O número de folhas por ocasião do florescimento exerceu maior influência no peso do fruto do que a altura da planta, diversamente do verificado por Cabral et al. (2009). Por sua vez, Kist et al. (2011) encontraram correlação positiva entre a massa do fruto e o comprimento da folha D para a cultivar 'Smooth Cayenne'. Destacamse, entre as correlações negativas e significativas, o teor de sólidos solúveis e a acidez, indicando a possibilidade de se colher frutos no estádio inicial ou intermediário de maturação para obter-se valores de acidez em faixas mais elevadas e adequadas ao consumo, semelhantes aos verificados para 'Smooth Cayenne' e 'Vitória' (VENTURA et al., 2009).

Aliado às boas características de peso, cor e qualidade físico-química do fruto, o abacaxi 'Turiaçu', nas condições atuais de cultivo, é considerado de maneira empírica pelos produtores regionais como cultivar resistente à fusariose, doença causada pelo fungo Fusarium subglutinans f.sp. ananas, que causa sérios prejuízos ao abacaxi 'Pérola' na região central do Estado. Testes de resistência com inoculação do fungo, em condições controladas, encontram-se em andamento na Universidade Estadual do Maranhão.

Conclui-se que a cultivar 'Turiaçu' apresenta frutos com características físicas e físico-químicas adequadas para consumo in natura. O peso médio do fruto de 1.620,0 g, coroa média, o teor de sólidos solúveis totais de $16,1^{\circ}$ Brix e a coloração amarela da polpa configuram um produto que atende às exigências comerciais. A elevada produção de filhotes por planta assegura a renovação e a ampliação das áreas de cultivo. 
TABELA 1- Características da planta, da folha e produção de mudas da cultivar Turiaçu, comparada com as cultivares Pérola, Smooth Cayenne e Vitória. São Luís-MA.

\begin{tabular}{lcccc}
\hline \multicolumn{1}{c}{ Característica } & Turiaçu & Pérola $^{\mathbf{1}}$ & $\begin{array}{c}\text { Smooth } \\
\text { Cayenne }^{1}\end{array}$ & Vitória $^{2}$ \\
\hline Epinescência da folha & espinhosa & espinhosa & parcial & sem espinhos \\
\hline Cor da folha & Verde-escuro & Verde- escuro & Verde-escuro & Verde- claro \\
\hline Altura da planta (cm) & 62,6 & 40,0 & 34,4 & - \\
\hline Comp. da folha D $(\mathrm{cm})$ & 83,8 & - & - & 92,8 \\
\hline Largura da folha D $(\mathrm{cm})$ & 5,15 & $9,5^{2}$ & $10,2^{2}$ & 10,48 \\
\hline Número de folhas & 61,0 & - & - & - \\
\hline Comp. do pedúnculo (cm) & 35,4 & 27,8 & 12,3 & - \\
\hline Diâmetro do pedúnculo (cm) & 2,8 & 2,8 & 3,0 & - \\
\hline Número de filhotes & 11,3 & 11,0 & 1,6 & 4,2 \\
\hline Número de rebentões & 0,6 & 0,2 & 1,8 & - \\
\hline ptado de Cabral et al. (2009). ${ }^{2}$ Adaptado de Ventura et al. (2009). & & &
\end{tabular}

TABELA 2- Características qualitativas do fruto da cultivar Turiaçu, comparada com as cultivares Pérola, Smooth Cayenne e Vitória. São Luís-MA.

\begin{tabular}{|c|c|c|c|c|}
\hline Característica & Turiaçu & Pérola $^{1}$ & $\begin{array}{c}\text { Smooth } \\
\text { Cayenne }^{1}\end{array}$ & Vitória $^{2}$ \\
\hline Forma do fruto & cilíndrico/cônico & cônico & cilíndrico & cilíndrico \\
\hline Cor da casca (fruto maduro) & amarelada & verde & alaranjada & amarela \\
\hline Cor da polpa & amarela & branca & amarelada & branca \\
\hline Peso do fruto com coroa $(\mathrm{g})$ & 1.620 & 1.650 & 2.314 & 1.557 \\
\hline Peso da coroa $(\mathrm{g})$ & 61,1 & 83,8 & 185,4 & 131 \\
\hline Peso do fruto sem coroa $(\mathrm{g})$ & 1.558 & 1.566 & 2.129 & 1.427 \\
\hline$\overline{\text { Diâmetro mediano }(\mathrm{cm})}$ & 10,4 & 12,6 & 14,2 & 12,0 \\
\hline Diâmetro do eixo central $(\mathrm{cm})$ & 2,5 & 2,4 & 2,8 & 1,2 \\
\hline Comp. fruto sem coroa $(\mathrm{cm})$ & 20,8 & 18,6 & 19,3 & - \\
\hline Comp. da coroa $(\mathrm{cm})$ & 14,4 & 17,4 & 19,0 & - \\
\hline Rendimento de polpa (\%) & 64,8 & - & - & - \\
\hline Sólidos solúveis totais ( ${ }^{\circ}$ Brix) & 16,1 & 13,7 & 13,9 & 15,8 \\
\hline Acidez total titulável (em \%) & 0,38 & 0,42 & 0,62 & 0,80 \\
\hline Relação SST/Acidez & 42,3 & 32,6 & 22,4 & 19,7 \\
\hline
\end{tabular}

'Adaptado de Cabral et al. (2009). ${ }^{2}$ Adaptado de Ventura et al. (2009).

TABELA 3- Coeficientes de correlação linear simples (r) entre variáveis físicas e fisico-químicas do fruto:AP: altura da planta; NF: número de folhas; CP: comprimento do pedúnculo; DP: diâmetro do pedúnculo; PF: peso do fruto; PC: peso da coroa; DT: diâmetro do talo (eixo); SST: sólidos solúveis totais; ATT: acidez total titulável e biométricas da planta da cultivar Turiaçu. São Luís- MA.

\begin{tabular}{ccccccccc}
\hline Variável & NF & CP & DP & PF & PC & DT & SST & ATT \\
\hline AP & 0,64 & $0,92^{* *}$ & 0,06 & 0,57 & $-0,81^{*}$ & $-0,07$ & 0,12 & $0,75^{*}$ \\
NF & & $0,88^{* *}$ & 0,29 & $0,73^{*}$ & $-0,76^{*}$ & 0,23 & 0,44 & 0,46 \\
CP & & & $0,72^{*}$ & -047 & $-0,85^{*}$ & 0,21 & 0,25 & 0,62 \\
DP & & & & 0,21 & $-0,34$ & $0,85^{* *}$ & 0,47 & 0,02 \\
PF & & & & & $0,78^{*}$ & $0,97^{* *}$ & $-0,33$ & $-0,68$ \\
PC & & & & & & 0,22 & $-0,42$ & $-0,70$ \\
DT & & & & & & & $-0,21$ & $-0,41$ \\
SST & & & & & & & $-0,96^{* *}$ \\
\hline
\end{tabular}

*Significativo pelo Teste $\mathrm{t}(\mathrm{p}<0.05)$; **Significativo pelo Teste $\mathrm{t}(\mathrm{p}<0.01)$. 


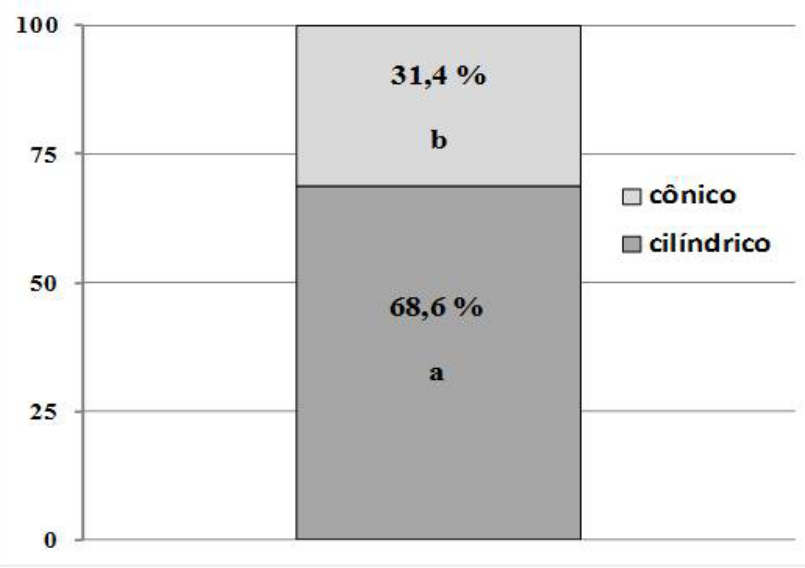

Médias diferem, estatisticamente, pelo Teste $\mathrm{t}(\mathrm{p}<0.01)$.

FIGURA 1- Proporção de frutos com formatos cilíndrico e cônico.

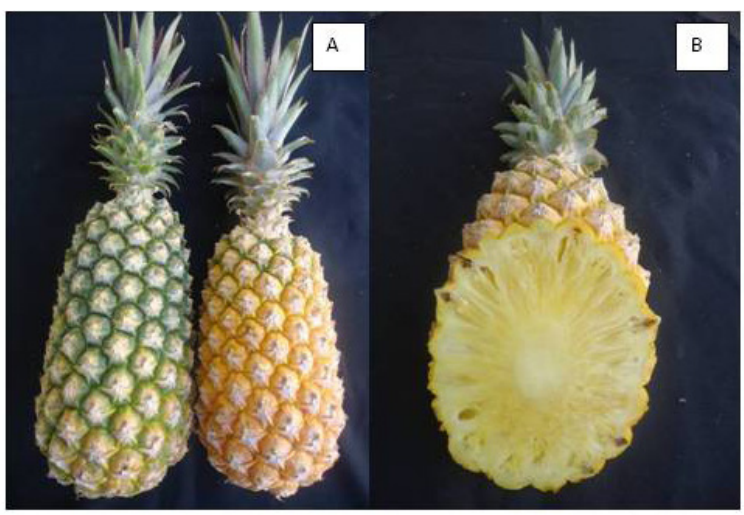

Fonte: Araújo, J.R.G.

FIGURA 2- Frutos de abacaxi ‘Turiaçu’ com detalhe da coloração da casca em dois estádios de maturação (A) e da polpa (B). São Luís-MA.

\section{REFERÊNCIAS}

ARAUJO, J.R.G.; MARTINS, M.R.; SANTOS, F. N. Fruteiras nativas - ocorrência e potencial de utilização na agricultura familiar do Maranhão. 2ed. In: MOURA, E.G. (Coord.). Agroambientes de transição entre o trópico úmido e o semi-árido do Brasil. São Luís: UEMA/IICA, 2007. p.257-312.

CABRAL, J.R.S.; LEDO, C.A.S.; CALDAS, R.C.; JUNGHANS, D.T. Variação de caracteres em híbridos de abacaxizeiro obtidos de diferentes cruzamentos. Revista Brasileira de Fruticultura, Jaboticabal, v.31, n.4, p.1129-1134, 2009.

CABRAL, J. R. S.; MATOS, A. P. Imperial, a new pineapple cultivar resistant to fusariosis. Acta Horticulturae, The Hague, v. 822, p. 47-50, 2009.
CRESTANI, M.; BARBIERI, R; HAWERROTH, F.J.; CARVALHO, J.I.F; OLIVEIRA, A,C. Das Américas para o mundo - origem, domesticação e dispersão do abacaxizeiro. Ciencia Rural, Santa Maria, v.40, n.6, p.1473-1483, 2010.

FAO - Food and Agriculture organization of the United Nations. FAOSTAT Countries by commodity. Pineapples, 2010. Disponível em: $<$ http: //faostat.fao.org/site/339/default.aspx >. Acesso em: 13 jan. 2012.

FERREIRA, F.R.; FÁVERO, A.P.; CABRAL, J.R.S.; SOUZA, F.V.D. Abacaxi-do-cerrado. In: VIEIRA, R.F. et al. (Ed.). Frutas nativas da região CentroOeste do Brasil. Brasília: Embrapa Informação Tecnológica, 2010. p.31-45. 
IBGE - INSTITUTO BRASILEIRO DE GEOGRAFIA E ESTATÍSTICA. Culturas temporárias e permanentes. Produção Agrícola Municipal, Rio de Janeiro, v. 37, p.1-91, 2010.

KIST, H.G.K; RAMOS, J.D.; SANTOS, V.A; RUFINI, J.C.M. Fenologia e escalonamento da produção do abacaxizeiro Smooth Cayenne no Cerrado de Mato Grosso. Pesquisa Agropecuária Brasileira, Brasília, v.46, n.9, p.992-997, 2011.

MAPA. Instrução Normativa/SARC n ${ }^{0} 01$, de 01 de fevereiro de 2002. Regulamento técnico de identidade e de qualidade para a classificação do abacaxi. Brasília, 2002.

SAMPAIO, A.C., FUMIS, T.F., LEONEL, S. Crescimento vegetativo e características dos frutos de cinco cultivares de abacaxi na região de Bauru-SP. Revista Brasileira de Fruticultura, Jaboticabal, v.33, n.3, p. 816-822, 2011.

SILVA, F.A.S.E.; AZEVEDO, C.A.V. A new version of the Assistat - Statistical Assistance Software. In: WORLD CONGRESS ON COMPUTERS IN AGRICULTURE, 4., 2006, Orlando. Proceedings... Orlando: American Society of Agricultural and
Biological Engineers, 2006. p.393-396.

SOUZA, F.V.D., CABRAL, J.R.S., SOUZA, H.E., SANTOS, O.S.N., SANTOS-SEREJO, J.A., FERREIRA, F.R. Caracterização morfológica de abacaxizeiros ornamentais. Magistra, Cruz das Almas, v. 19, n.4, p. 319-325, 2007.

SPIRONELLO, A. Abacaxi. In: DONADIO, L.C. (Org.). História da fruticultura paulista. Jaboticabal: SBF, 2010. p.62-82.

VENTURA, J. A.; COSTA, H.; CABRAL, J. R. S.; MATOS, A. P. Vitória: new pineapple cultivar resistent to fusariosis. Acta Horticulturae, The Hague, v. 822, p. 51- 56, 2009. 